\title{
Formation of $\beta-\mathrm{Bi}_{2} \mathrm{O}_{3}$ and $\delta-\mathrm{Bi}_{2} \mathrm{O}_{3}$ during laser irradiation of $\mathrm{Bi}$ films studied in-situ by spatially resolved Raman spectroscopy
}

\author{
C. Díaz-Guerra ${ }^{\text {a, }}{ }^{*}$, P. Almodóvar ${ }^{\text {a }}$, M. Camacho-López ${ }^{\text {b }}$, S. Camacho-López ${ }^{\mathrm{c}}$, J. Piqueras ${ }^{\mathrm{a}}$ \\ ${ }^{a}$ Departamento de Física de Materiales, Facultad de Ciencias Físicas, Universidad Complutense de Madrid, Ciudad Universitaria s/n, 28040, Madrid, Spain \\ ${ }^{\mathrm{b}}$ Laboratorio de Investigación y Desarrolo de Materiales Avanzados, Facultad de Química, Universidad Autónoma del Estado de México, Campus Rosedal, \\ Km 14.5 Carretera Toluca-Atlacomulco, San Cayetano de Morelos, Toluca, C.P. 50925, Mexico \\ ${ }^{c}$ Departamento de Óptica, Centro de Investigación Científica y de Educación Superior de Ensenada, Carretera Ensenada-Tijuana 3918, Zona Playitas, \\ Ensenada, Baja California, 22860, Mexico
}

\section{A R T I C L E I N F O}

\section{Article history:}

Received 26 March 2017

Received in revised form

23 June 2017

Accepted 24 June 2017

Available online 26 June 2017

\section{Keywords:}

Oxide materials

Laser processing

Phase transitions

Inelastic light scattering

\begin{abstract}
A B S T R A C T
The formation of different phases of $\mathrm{Bi}_{2} \mathrm{O}_{3}$ induced by laser irradiation of $\mathrm{Bi}$ films has been assessed in situ by micro-Raman spectroscopy as a function of laser wavelength, power density and irradiation time. Raman mapping of the irradiated samples enabled a spatially-resolved study of the distribution of the formed $\mathrm{Bi}_{2} \mathrm{O}_{3}$ phases. Red laser $(633 \mathrm{~nm})$ irradiation was found to induce the appearance of $\beta-\mathrm{Bi}_{2} \mathrm{O}_{3}$, within a certain range of power densities, by diffusion-controlled processes. In contrast, ultraviolet (UV, $325 \mathrm{~nm}$ ) laser irradiation, above a certain power density threshold, initially induces the formation of both $\beta$ and $\delta$ - $\mathrm{Bi}_{2} \mathrm{O}_{3}$ phases. The amount of the produced $\delta$ - $\mathrm{Bi}_{2} \mathrm{O}_{3}$ phase increases by increasing the irradiation time, while that of the $\beta$ phase follows the opposite trend. UV laser irradiation seems to be a suitable method to produce room temperature stable $\delta-\mathrm{Bi}_{2} \mathrm{O}_{3}$ patterns on $\mathrm{Bi}$ films.
\end{abstract}

() 2017 Elsevier B.V. All rights reserved.

\section{Introduction}

Laser irradiation is a powerful and versatile way to modify the structure, composition and physical properties of a wide range of materials, including semiconductors [1-3] and metallic alloys [4]. In particular, laser irradiation is a suitable technique to obtain metal oxides complex structures at room temperature in short times and with rather low energy consumption. Contrary to conventional thermal oxidation of metals achieved by furnace annealing, continuous wave laser or pulsed-laser irradiation allows to induce extremely localized surface modifications within well-defined regions, determined by the laser characteristics and physical properties of the material [5,6]. Within this context, nano and micropatterning of different structures like photomasks and diffractive optical elements can be achieved [7,8]. Laser-induced oxidation of $\mathrm{Ti}$ [7], Bi [9,10], Mo [11] and Fe [12] have been reported in the last years. In addition to local metal oxidation, laser irradiation has been reported to induce phase transitions in different semiconductor oxides of technological interest, such as anatase to rutile in $\mathrm{TiO}_{2}$ [1], $\alpha$ to $\delta$ phases in $\mathrm{Bi}_{2} \mathrm{O}_{3}$ [13], $\mathrm{MoO}_{2}$ to $\alpha$ $\mathrm{MoO}_{3}$ [2] or several phase changes in $\mathrm{Sb}_{2} \mathrm{O}_{3}$ [14].

\footnotetext{
* Corresponding author

E-mail address: cdiazgue@ucm.es (C. Díaz-Guerra).
}

Bismuth trioxide $\left(\mathrm{Bi}_{2} \mathrm{O}_{3}\right)$ is a wide band-gap semiconductor with a high refractive index, ionic conductivity and good photoconductive response, with potential applications in optoelectronics, gas sensing, photocatalysis, Li-ion batteries and other fields of technological interest [15-19]. An important characteristic of this oxide is the existence of four main polymorphs, labelled as $\alpha$ (monoclinic), $\beta$ (tetragonal), $\gamma(b c c)$ and $\delta(f c c)$, with different electronic and optical properties. $\alpha-\mathrm{Bi}_{2} \mathrm{O}_{3}$ is stable from room temperature up to $730{ }^{\circ} \mathrm{C}$. Above this temperature, it transforms into the $\delta-\mathrm{Bi}_{2} \mathrm{O}_{3}$ phase, which remains stable up to its melting point $\left(825^{\circ} \mathrm{C}\right)$. During cooling of the $\delta$ phase, two metastable phases $\beta$ and $\gamma$, may be obtained. Such phases usually transform into $\alpha-\mathrm{Bi}_{2} \mathrm{O}_{3}$ below approximately $640^{\circ} \mathrm{C}$. From the point of view of applications, the $\beta$ and $\delta \mathrm{Bi}_{2} \mathrm{O}_{3}$ polymorphs are of particular interest. $\beta-\mathrm{Bi}_{2} \mathrm{O}_{3}$ shows an excellent photocatalytic activity and recent studies provide strong evidence that this material can be used for sustainable water treatment applications [20]. The high-temperature $\delta-\mathrm{Bi}_{2} \mathrm{O}_{3}$ phase is one of the best oxygen ion conductors known and it is considered as a reference material within the field of solid electrolytes [21]. Nevertheless, its limited temperature stability range and poor performance in reducing atmospheres has fostered the development of different synthesis routes in order to stabilize this phase at lower temperatures $[21,22]$ and improve its chemical stability in 
reactive environments, yet maintaining a high ionic conductivity [21]. Previous works have reported on the stable formation of $\beta$ $\mathrm{Bi}_{2} \mathrm{O}_{3}$ and $\alpha-\mathrm{Bi}_{2} \mathrm{O}_{3}$ by laser-induced oxidation of $\mathrm{Bi}[9,10,23,24]$, evidencing that the obtained oxide phase critically depends not only on the irradiation parameters (continuous wave or pulsed beam, irradiation time and laser power), but also on the grain size of the Bi sample. However, none of these works investigated the spatial distribution of the obtained phases, while only in Ref. [10] a real-time in situ assessment - able to provide useful information for process control and to elucidate the transformation kinetics - was carried out.

In this work, we studied laser-induced oxidation of Bi thin films for $325 \mathrm{~nm}$ and $633 \mathrm{~nm}$ wavelength, under different laser power densities and for different irradiation times. Formation of either $\beta$ $\mathrm{Bi}_{2} \mathrm{O}_{3}$ or predominantly $\delta-\mathrm{Bi}_{2} \mathrm{O}_{3}$ was achieved depending on the irradiation conditions. The latter has not been reported in the literature on laser-induced oxidation of $\mathrm{Bi}$. The growth of such phases, its corresponding transformation dynamics and their temporal stability has been studied in-situ by micro-Raman spectroscopy, while Raman mapping was used to determine their spatial distribution.

\section{Experimental}

Bismuth thin films, approximately $500 \mathrm{~nm}$ thick, were grown on glass substrates by DC magnetron sputtering with a Bi target in $\mathrm{Ar}$ atmosphere, as described in Ref. [23]. XRD patterns evidenced that the films were polycrystalline and made of pure rhombohedral bismuth [23]. Micro-Raman measurements were carried out at room temperature in a Horiba Jovin-Ybon LabRAM HR800 system. The samples were irradiated either by a $325 \mathrm{~nm} \mathrm{He}-\mathrm{Cd}$ laser or by a $633 \mathrm{~nm}$ He-Ne laser on an Olympus BX 41 confocal microscope. The size of the laser spot on the sample was $2 \mu \mathrm{m}$ approximately. The laser power density was adjusted by using a set of neutral density filters. The morphology of the samples, prior and after laser irradiation, was characterized by using a FEI Inspect S scanning electron microscope (SEM). The composition of the films was assessed by X-ray photoelectron spectroscopy (XPS) and energy dispersive X-ray microanalysis (EDS). XPS measurements were acquired with a JEOL JPS-9200 system, equipped with a Mg X-ray source $(1253.6 \mathrm{eV})$ at $200 \mathrm{~W}$. SEM-EDS measurements were carried out using a Bruker AXS Quantax system.

\section{Results and discussion}

XPS measurements of the as-grown Bi films reveal, besides adventitious $\mathrm{C}$ and $\mathrm{O}$, the absence of elements other than bismuth (see Supplementary information). Since XPS is a surface characterization technique, providing in this case information from a depth of about $7 \mathrm{~nm}$, XPS measurements have been complemented by SEM-EDS, which is able to probe the whole thickness of the Bi film. Besides very weak signals corresponding to C and O, EDS spectra show peaks corresponding just to bismuth (see Supplementary material), in good agreement with XPS and XRD data.

\subsection{Red laser (633 $\mathrm{nm}$ ) irradiation}

An example corresponding to a Bi film irradiated for $10 \mathrm{~s}$ with a laser power density of $4.8 \times 10^{4} \mathrm{~W} / \mathrm{cm}^{2}$ is shown in Fig. 1. SEM images of the as-grown Bi films show polyhedral crystals with sizes between 50 and $500 \mathrm{~nm}$ approximately (Fig. 1a). Raman spectra (Fig. 1b) show two main peaks centred at $70 \mathrm{~cm}^{-1}$ and $96 \mathrm{~cm}^{-1}$, corresponding to $E_{g}$ and $A_{1 \mathrm{~g}}$ phonon modes of rhombohedral $\mathrm{Bi}$. A weaker peak at about $185 \mathrm{~cm}^{-1}$ is attributed to second-order
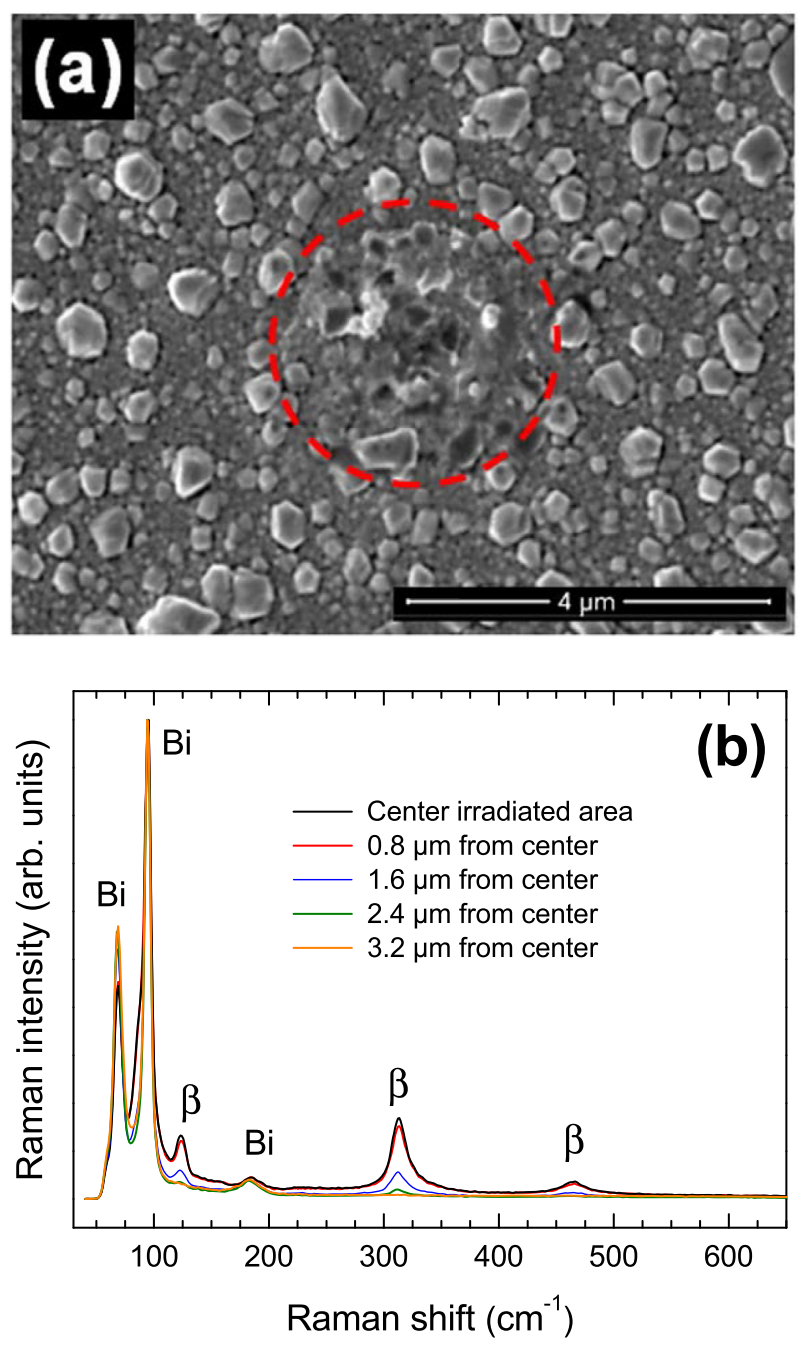

Fig. 1. (a) SEM image of Bi film irradiated with the $633 \mathrm{~nm}$ laser for $10 \mathrm{~s}$ with a $4.8 \times 10^{4} \mathrm{~W} / \mathrm{cm}^{2}$ power density, showing the original morphology of the sample and the changes induced by the irradiation process (encircled). (b) Raman spectra acquired with a $2 \times 10^{3} \mathrm{~W} / \mathrm{cm}^{2}$ power density at increasing distances from the irradiated area. The spectrum recorded at $3.2 \mu \mathrm{m}$ is representative of the as-grown Bi film.

harmonics [24]. Irradiation with the $633 \mathrm{~nm}$ laser beam does not induce the formation of any $\mathrm{Bi}_{2} \mathrm{O}_{3}$ phase for power densities below $\sim 2 \times 10^{4} \mathrm{~W} / \mathrm{cm}^{2}$, even after prolonged irradiation times. Above this threshold, Raman spectra show three additional peaks centred near 124,315 and $465 \mathrm{~cm}^{-1}$, which are characteristic $\mathrm{Bi}-\mathrm{O}$ stretching modes of the $\beta-\mathrm{Bi}_{2} \mathrm{O}_{3}$ phase [25]. SEM observations reveal a clear morphological transformation inside the irradiated area (encircled in Fig. 1a), while the intensity of the three abovementioned $\beta-\mathrm{Bi}_{2} \mathrm{O}_{3}$ Raman peaks decreases with increasing distance to the irradiation centre (Fig. 1b) due to the Gaussian intensity profile of the laser beam. Fig. 2 shows an optical micrograph of the same irradiated area and five Raman mappings corresponding to the wavenumber ranges where the main Bi peaks (65-75) and (90-99) $\mathrm{cm}^{-1}$, and to those related to the $\beta-\mathrm{Bi}_{2} \mathrm{O}_{3}$ signals; $(115-130) \mathrm{cm}^{-1},(280-350)$ $\mathrm{cm}^{-1}$ and (445-485) $\mathrm{cm}^{-1}$ show up. These spectral images indicate the presence of $\beta-\mathrm{Bi}_{2} \mathrm{O}_{3}$ up to a distance of about $2.5 \mu \mathrm{m}$ from the centre and clearly show that the spatial distribution of the oxide is anti-correlated with that of the metal. The intensity of the Raman signal kept constant even two days after the irradiation was carried out, revealing the high temporal stability of the obtained $\beta-\mathrm{Bi}_{2} \mathrm{O}_{3}$ phase. It should be also mentioned that the formation of $\alpha-\mathrm{Bi}_{2} \mathrm{O}_{3}$, 

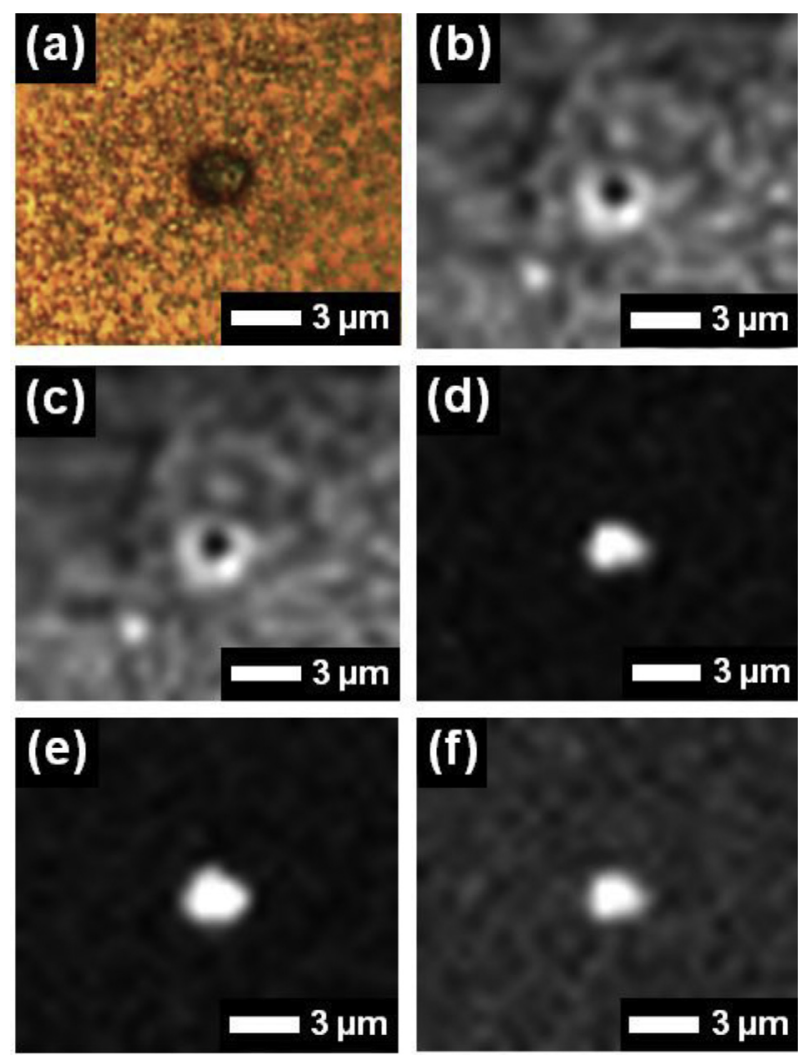

Fig. 2. Optical micrograph (a) and Raman intensity mappings, recorded at the irradiated area shown in Fig. 1(a), of the Bi peaks centred at $70 \mathrm{~cm}^{-1}$ (b) and $96 \mathrm{~cm}^{-1}$ (c), and the $\beta-\mathrm{Bi}_{2} \mathrm{O}_{3}$ peaks centred at $124 \mathrm{~cm}^{-1}$ (d), $315 \mathrm{~cm}^{-1}$ (e) and $465 \mathrm{~cm}^{-1}$ (f).

which is the stable $\mathrm{Bi}_{2} \mathrm{O}_{3}$ phase at room temperature, was not observed under the experimental conditions used (laser power densities from $2 \times 10^{2}$ to $2 \times 10^{5} \mathrm{~W} / \mathrm{cm}^{2}$ ). Moreover, irradiation with a $\sim 2 \times 10^{5} \mathrm{~W} / \mathrm{cm}^{2}$ power density readily melts the Bi film, giving no time to the oxidation process to take place (see Supplementary information). The results shown in the present work are completely reproducible in terms of the final $\mathrm{Bi}_{2} \mathrm{O}_{3}$ phase formed, its temporal stability and the experimental conditions needed to obtain such phase. Different results have been reported regarding the formation of the $\alpha$ and $\beta-\mathrm{Bi}_{2} \mathrm{O}_{3}$ phases by laserinduced oxidation of Bi films. For instance, increasing power density favoured the formation of $\alpha-\mathrm{Bi}_{2} \mathrm{O}_{3}$ in Ref. [10], while only the $\beta$ phase was found in Ref. [23] and in the present work. The appearance of both phases was reported for intermediate laser powers [10]. In addition to the laser power, the influence of another parameter on the $\mathrm{Bi}_{2} \mathrm{O}_{3}$ phases obtained by laser irradiation, namely the roughness of the Bi film surface, on the obtained $\mathrm{Bi}_{2} \mathrm{O}_{3}$ phases has been demonstrated [10]. Actually, Raman studies of laser-induced oxidation carried out in Bi films of different roughness and particle sizes, revealed that the $\beta$ phase was initially formed in all cases, but the results suggested that such phase was not retained above a critical particle size of about $1.5 \mu \mathrm{m}$ and it was partially transformed into the $\alpha$-phase. Moreover, differences in the relative texture of the particulates were found to be irrelevant when compared to size - in determining the synthesized oxide phase. These findings indicate the existence of a critical oxide grain size for which the transition from $\beta$ to $\alpha-\mathrm{Bi}_{2} \mathrm{O}_{3}$ takes place. For a $633 \mathrm{~nm}$ laser and a beam spot size of $1.7 \mu \mathrm{m}$, which is similar to that used in the present work, noticeably only the $\beta-\mathrm{Bi}_{2} \mathrm{O}_{3}$ phase was obtained in Ref. [10]. This is in good agreement with the present results obtained in Bi films with crystal sizes in the submicron range (Fig. 1).

The study of the transformation kinetics from rhombohedral $\mathrm{Bi}$ to tetragonal $\beta-\mathrm{Bi}_{2} \mathrm{O}_{3}$ was carried out by measuring the intensity of the $315 \mathrm{~cm}^{-1}$ Raman peak as a function of the irradiation time. For these measurements, the power density was set to $9 \times 10^{4} \mathrm{~W} / \mathrm{cm}^{2}$. Fig. $4 \mathrm{a}$ shows that the intensity of the $315 \mathrm{~cm}^{-1}$ peak increases steeply and it reaches its maximum in about $20 \mathrm{~s}$. Assuming that the intensity of the $315 \mathrm{~cm}^{-1}$ peak was proportional to the volume of $\mathrm{Bi}$ transformed into $\beta-\mathrm{Bi}_{2} \mathrm{O}_{3}$, the experimental data were fitted to the Johnson-Mehl-Avrami-Kolmogorov (JMAK) equation [26-28]:

$\mathrm{X}=1-\exp \left(-\mathrm{Kt}^{n}\right)$

where $\mathrm{X}$ is the transformed volume fraction in the irradiated zone, $\mathrm{K}$ is an effective rate constant and the Avrami exponent $n$ depends on the mechanisms of transport, nucleation and growth. The JMAK equation is adequate to describe isothermal crystallization kinetics under several assumptions, such as a random distribution of particle nuclei, isotropic growth and constant particle growth rate. It has been frequently applied to describe phase transformations induced by laser irradiation in different materials $[2,13,29]$ and also used as a suitable approximation in many transformations not strictly fulfilling the previously mentioned conditions due to its simplicity and robustness [30]. Fig. 3b shows the Avrami plot of the data, showing a time-dependent Avrami exponent with two regimes with $n$ values close to 1 and 0.5 , respectively. The stage with $n=1$ may correspond to a diffusion controlled bi-dimensional reaction with nucleation site saturation [31]. The results here obtained for irradiation with a red laser reveal a change in the oxide formation mechanism, which is evidenced by a change of the Avrami exponent. The rate of oxidation depends on the mass transfer rate of oxygen from the gas phase to the surface, the chemical rate of oxidation of the surface, and the diffusion of oxygen from the reacting surface to the interior of the Bi film. Actually, this situation resembles previous investigations on the oxidation of other metals, such as copper, revealing that the initial stages of oxidation are dominated by surface diffusion of oxygen [32]. Avrami exponents smaller than one are commonly attributed to confined diffusion-controlled growth processes [33]. In the present case, the observed second oxidation regime is characterized by an Avrami exponent $\mathrm{n}=0.5$. Such exponent has been previously attributed to a diffusion controlled growth by thickening of large plates [28] and suggests a reduction in the growth rate of the oxide, due the change of surface oxidation to diffusion through an oxide layer. Steele and Lewis [34] also observed the appearance of two oxidation regimes in their study of laser-induced oxidation of $\mathrm{Bi}$ microdroplets on GaAsBi films, but higher $n$ values were reported. As stated before, this might be related to the different grain size and morphology of the irradiated samples in that work [10,34].

\subsection{UV laser (325 $\mathrm{nm}$ ) irradiation}

The effects of irradiation with the $325 \mathrm{~nm}$ laser (UV light) significantly differ from those relative to the $633 \mathrm{~nm}$ (red light) irradiation. In this case, no $\mathrm{Bi}_{2} \mathrm{O}_{3}$ phases were detected by Raman spectroscopy for power densities below $\sim 3 \times 10^{2} \mathrm{~W} / \mathrm{cm}^{2}$, even after prolonged irradiation times. Fig. 4a shows a SEM image of a Bi film irradiated for $5 \mathrm{~min}$ with a laser power density of $1.3 \times 10^{4} \mathrm{~W} / \mathrm{cm}^{2}$. Crystals with well-defined faces are no longer observed in the irradiated area, where a local melting and resolidification process seems to have taken place. Raman spectra recorded at different positions within the irradiated area (Fig. 4b) show the $\mathrm{B}_{-} \mathrm{Bi}_{2} \mathrm{O}_{3}$ peaks at 122 and $313 \mathrm{~cm}^{-1}$, which were also present in the samples irradiated with the red laser. Much weaker peaks can be observed near 221, 250, 298 and $366 \mathrm{~cm}^{-1}$. These peaks have not been 

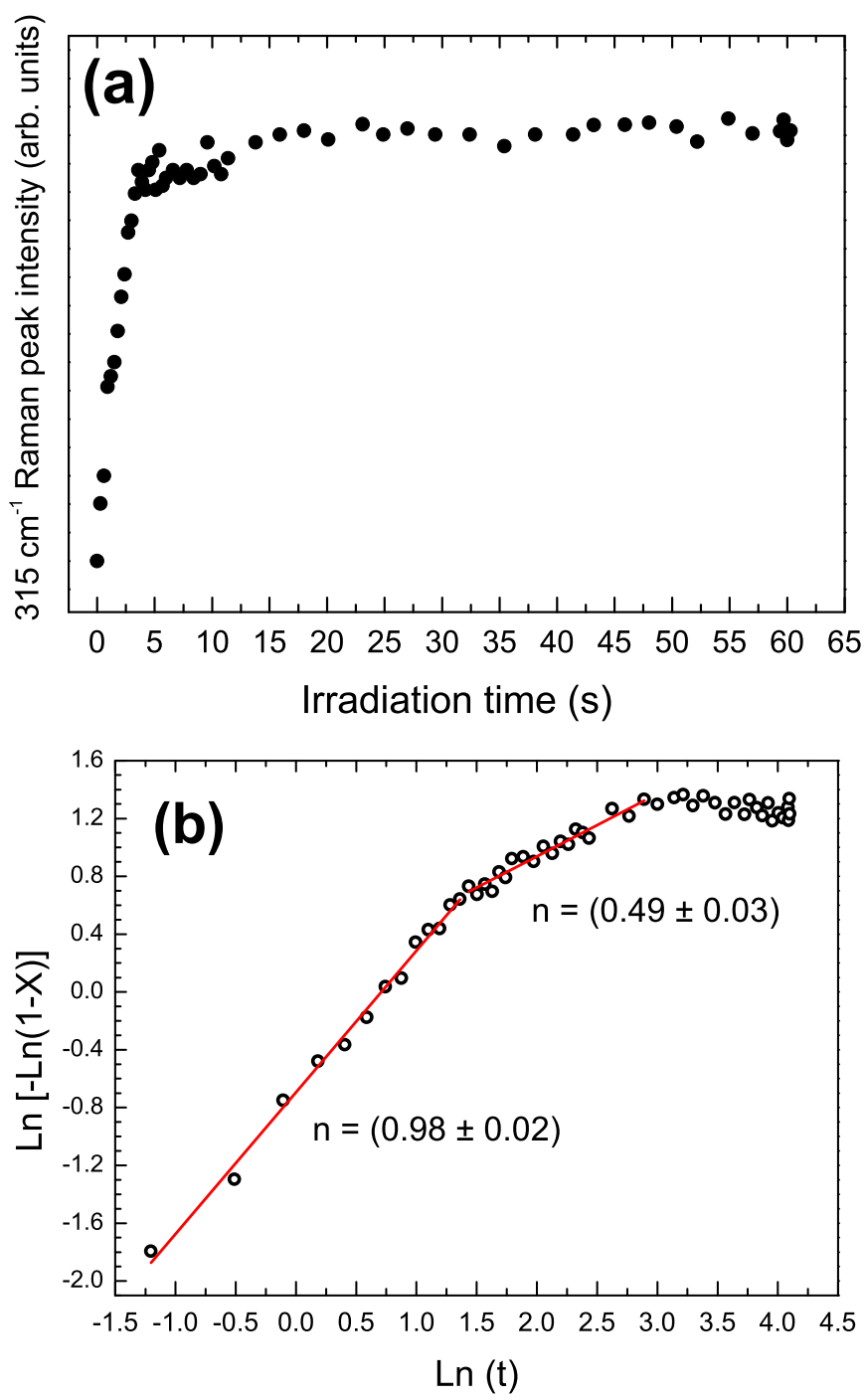

Fig. 3. (a) Temporal intensity evolution of the $\beta-\mathrm{Bi}_{2} \mathrm{O}_{3} 315 \mathrm{~cm}^{-1}$ Raman peak (a) and the corresponding Avrami plot (b). (Red laser irradiation, $9 \times 10^{4} \mathrm{~W} / \mathrm{cm}^{2}$ power density).

reported in previous Raman studies of any known $\mathrm{Bi}_{2} \mathrm{O}_{3}$ phase [25,35-38] and are tentatively attributed to Bi sub-stoichiometric oxides formed during irradiation. Nevertheless, the most significant feature observed in these spectra is the appearance of an intense peak at about $630 \mathrm{~cm}^{-1}$, which is characteristic of the $f c c \delta$ $\mathrm{Bi}_{2} \mathrm{O}_{3}$ phase [37,38]. This peak shows a weak shoulder at higher wavenumbers, which suggests that the signal is of a complex nature. Fig. 4c illustrates the Lorentzian deconvolution of the $630 \mathrm{~cm}^{-1}$ peak into three components at 595, 630 and $655 \mathrm{~cm}^{-1}$, the relative weight of which were found to be constant across the irradiated area (see Supplementary information). This complex character has been previously reported in Raman investigations of $\delta-\mathrm{Bi}_{2} \mathrm{O}_{3}[13,37,38]$ and it is probably related to the complicated disorder of the oxygen sublattice characteristic of this phase [39]. It should be also mentioned that irradiation with the maximum power density available $\left(\sim 3 \times 10^{4} \mathrm{~W} / \mathrm{cm}^{2}\right)$ yield similar results to those shown in Fig. 4. However, UV irradiation with a laser power density of $\sim 3.3 \times 10^{2} \mathrm{~W} / \mathrm{cm}^{2}$ was found to induce the formation of the $\delta-\mathrm{Bi}_{2} \mathrm{O}_{3}$ phase without altering the original morphology of the Bi film. This reduced power density decreases the temperature gradient induced by the laser beam and the transformed region
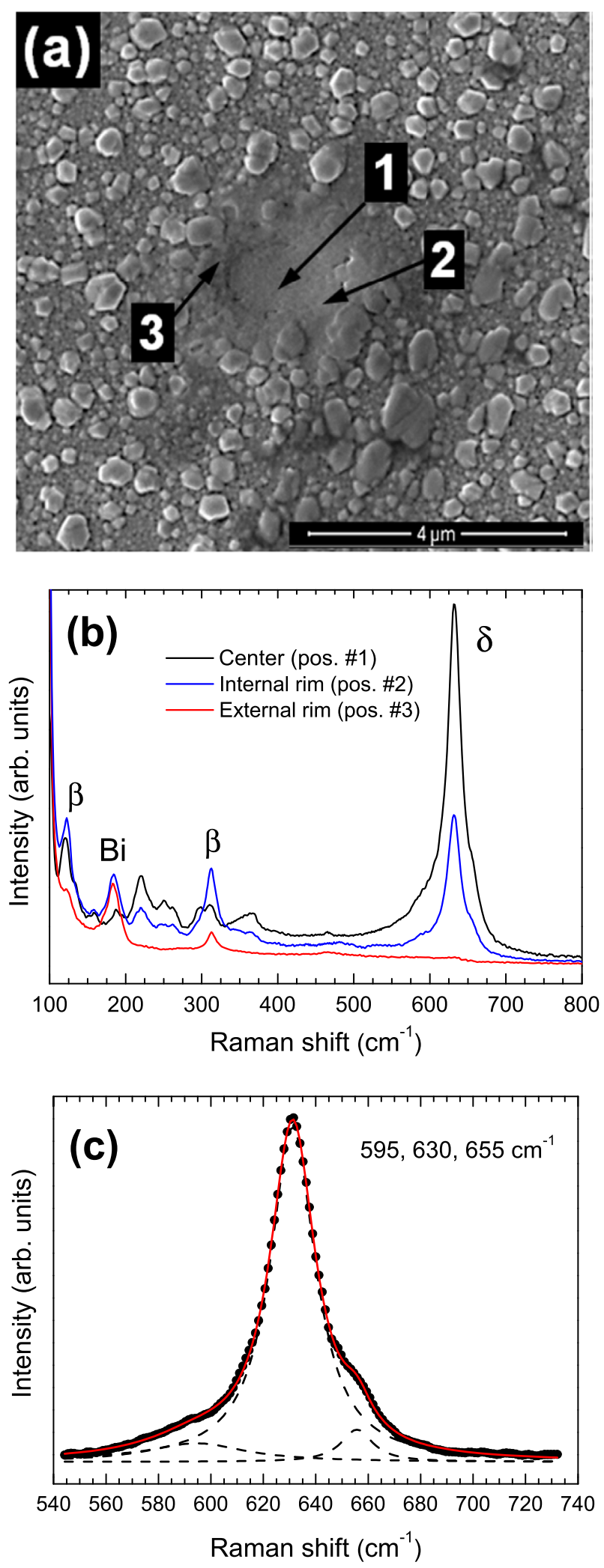

Fig. 4. (a) SEM image of Bi film irradiated with the $325 \mathrm{~nm}$ UV laser for 5 min with a $1.3 \times 10^{4} \mathrm{~W} / \mathrm{cm}^{2}$ power density. (b) Raman spectra acquired at different positions of the same irradiated area. (c) Lorentzian fitting of the $630 \mathrm{~cm}^{-1} \delta-\mathrm{Bi}_{2} \mathrm{O}_{3}$ Raman signal. Deconvolution reveals three components peaked at 595, 630 and $655 \mathrm{~cm}^{-1}$. 
probably restricts to the surface of the film. This surface oxidation can be visualized as a contrast change in the corresponding SEM image (see Supplementary information). In all cases, Raman spectra recorded five days after the irradiation was performed showed no intensity decrease of the $\delta-\mathrm{Bi}_{2} \mathrm{O}_{3} 630 \mathrm{~cm}^{-1}$ peak. Raman mappings recorded within the irradiated area shown in Fig. 4a at wavenumbers characteristic of the $\beta$ and $\delta-\mathrm{Bi}_{2} \mathrm{O}_{3}$ spectra show a similar spatial distribution of both phases (Fig. 5). As in the case of $633 \mathrm{~nm}$ irradiation, these spectral images show that the spatial distribution of both oxides is anti-correlated to that of bismuth.

Transformation kinetics was investigated in-situ by using a laser power density of $6.5 \times 10^{3} \mathrm{~W} / \mathrm{cm}^{2}$, as it allowed the oxidation reactions to occur on a resolvable timescale. The formation of the $\delta$ and $\beta$ phases was respectively monitored through the evolution of the intensities of the 625 and $313 \mathrm{~cm}^{-1}$ Raman peaks with the irradiation time. The appearance of both phases is observed after irradiating the films for just $10 \mathrm{~s}$. Fig. 6 a shows that the intensity of the $625 \mathrm{~cm}^{-1}$ peak remains almost constant up to $700 \mathrm{~s}$ of irradiation and then it increases until reaching a saturation value at about $2100 \mathrm{~s}$. On the contrary, the intensity of the $313 \mathrm{~cm}^{-1}$ peak (characteristic of the $\beta$ phase) decreases by increasing the irradiation time until reaching a constant value after $1600 \mathrm{~s}$ (Fig. 6b). The Avrami plot corresponding to the $\delta$ phase formation is shown in Fig. 6c. The calculated Avrami exponent $n$ is approximately 3, which might correspond to a two-dimensional interface controlled growth [40]. These results indicate that both phases, $\beta$ and $\delta$, are formed at the early stages of the irradiation process and suggest that the $\beta$ phase is progressively transformed into the $\delta$ phase.

Conventional thermal oxidation of Bi films strongly depends on the heating rate and atmosphere and the process obeys parabolic laws that usually describe oxidation of metallic surfaces exposed to high temperatures and free oxygen [41]. However, this is not the case in the present work, neither for the red laser nor for the UV laser irradiation, since our experimental data evidence that in both cases the growth rate laws are described by logarithmic functions. This might be explained by the rapid and well spatially confined rising of temperature induced by the laser annealing, as compared with conventional furnace annealing. Interpretations of the logarithmic laws have been based on the adsorption of reactive species, the effects of electric fields developed across oxide layers, tunnelling of electrons through the thin scales, progressive blocking of low-resistance diffusion paths, non-isothermal conditions in the
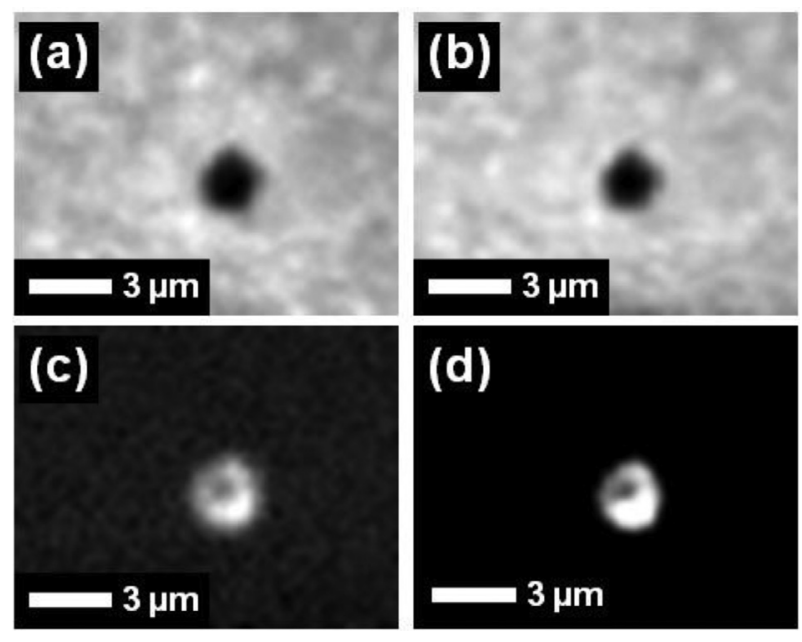

Fig. 5. Raman intensity mappings, recorded at the irradiated area shown in Fig. 4(a), of the $\mathrm{Bi}$ peaks centred at $70 \mathrm{~cm}^{-1}(\mathrm{a})$ and $96 \mathrm{~cm}^{-1}(\mathrm{~b})$, the $\beta-\mathrm{Bi}_{2} \mathrm{O}_{3}$ peak centred at $313 \mathrm{~cm}^{-1}$ (c) and the $\delta-\mathrm{Bi}_{2} \mathrm{O}_{3}$ peak centred at $630 \mathrm{~cm}^{-1}$ (d).
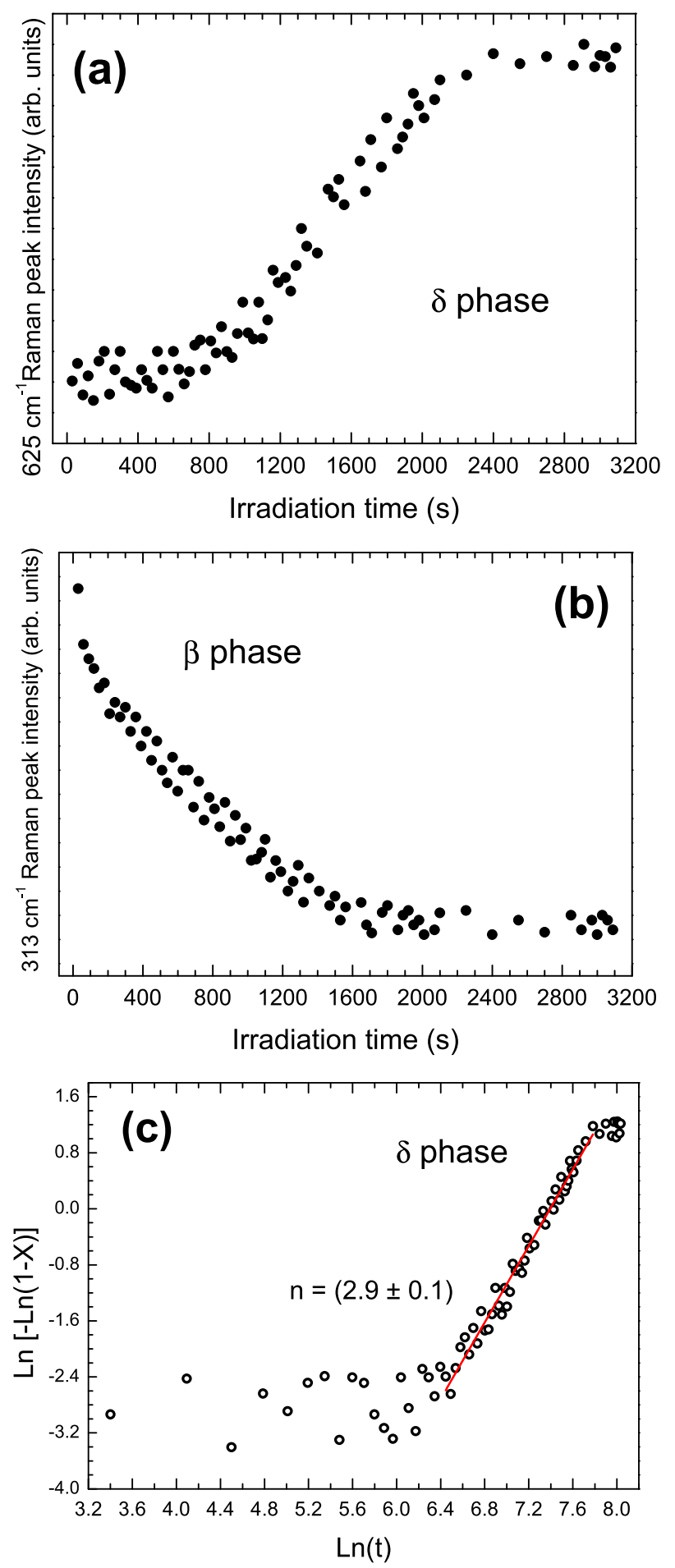

Fig. 6. Temporal intensity evolution of the $\delta-\mathrm{Bi}_{2} \mathrm{O}_{3} 625 \mathrm{~cm}^{-1}$ (a) and $\beta-\mathrm{Bi}_{2} \mathrm{O}_{3}$ $313 \mathrm{~cm}^{-1}$ (b) Raman peaks. (c) Avrami plot corresponding to the $\delta$ phase formation (UV laser irradiation, $6.5 \times 10^{3} \mathrm{~W} / \mathrm{cm}^{2}$ power density).

oxide layer, etc. The interplay between such varieties of physicalchemical phenomena actually makes the interpretation of the logarithmic rate behaviour the least-understood area of metal oxidation [41]. In fact, as pointed out in another investigation [10], the fundamental relationships between bismuth oxidation and ensuing phases are still unresolved. The results obtained in previous studies $[10,34]$ and in the present work, support that formation of an initial $\beta-\mathrm{Bi}_{2} \mathrm{O}_{3}$ takes place before the formation and 
stabilization of any other bismuth oxide phase, which was explained by an electrostatic model based on the changing $\mathrm{Bi}_{2} \mathrm{O}_{3}$ surface-to-volume ratio. Our findings certainly do not contradict this view. Nevertheless, while red laser irradiation of particles above a critical size was found to induce - after passing through an intermediate $\beta$-phase - the growth of $\alpha-\mathrm{Bi}_{2} \mathrm{O}_{3}$, our work reveals that UV laser irradiation induces the formation of the much more technologically interesting $\delta$ phase. This phase remains stable at room temperature in the present case, which is a remarkable fact. Room temperature stabilization of $\delta-\mathrm{Bi}_{2} \mathrm{O}_{3}$ has been previously achieved without intentional doping by epitaxial growth techniques, which is explained to a great extent by adequate strain relaxation and small grain sizes $[42,43]$. This might be also the case in the present work, where the oxide formation takes place in a spatially confined area related to the laser beam size. In this context, the photon energy of the laser light used to irradiate the samples is an important factor. The UV laser energy (325 nm-3.82 eV) is higher than the $\beta-\mathrm{Bi}_{2} \mathrm{O}_{3}$ band gap energy $(\sim 2.6 \mathrm{eV})$ [44], while that of the red laser $(633 \mathrm{~nm}-1.96 \mathrm{eV})$ is below that value. The resulting differences in the absorption efficiencies could explain why red laser irradiation is unable to induce the formation of $\delta-\mathrm{Bi}_{2} \mathrm{O}_{3}$ even for power densities higher than those able to induce such transformation with the UV laser. As stated above, many aspects of phase transformation relations among the different $\mathrm{Bi}_{2} \mathrm{O}_{3}$ polymorphs are still not well understood. Nevertheless, a $\beta$ to $\delta$ phase transition has been reported to take place at about $665{ }^{\circ} \mathrm{C}$ [45]. The metal atom distribution in both oxides is rather similar and differences in the structure must be attributed only to the oxygen sublattice [39]. Actually, the existence of a tetragonal transition phase $\mathrm{Bi}_{2} \mathrm{O}_{2.7}$ has been proposed [46] in the transformation from $\beta$ to $\delta-\mathrm{Bi}_{2} \mathrm{O}_{3}$. Weak Raman peaks observed in this work, not corresponding to any known $\mathrm{Bi}_{2} \mathrm{O}_{3}$ phase, might be related to such phase. The laser-induced transformation of $\mathrm{Bi}$ into $\delta$ $\mathrm{Bi}_{2} \mathrm{O}_{3}$ differs from previous reports, in which laser irradiation was found to lead to the formation of either the $\alpha$ or $\beta$ phases or a mixture of both. Laser-induced formation of $\delta-\mathrm{Bi}_{2} \mathrm{O}_{3}$ has only been previously reported as an $\alpha$ to $\delta$ transformation in $\mathrm{Bi}_{2} \mathrm{O}_{3}$ ceramics and nanowires [13].

\section{Conclusions}

In summary, the formation of different $\mathrm{Bi}_{2} \mathrm{O}_{3}$ phases induced by laser irradiation of Bi films has been assessed in situ by microRaman spectroscopy, as a function of laser wavelength, power density and time. Red laser $(633 \mathrm{~nm})$ irradiation induces the formation of $\beta-\mathrm{Bi}_{2} \mathrm{O}_{3}$ within a certain range of power densities. The oxidation dynamics can be described by the JMAK equation and it appears to be triggered by diffusion processes. UV $(325 \mathrm{~nm})$ irradiation above a certain power density threshold initially induces the formation of the $\beta$ and predominantly the $\delta-\mathrm{Bi}_{2} \mathrm{O}_{3}$ phases. Raman mapping shows a similar spatial distribution of both phases. The amount of the produced $\delta-\mathrm{Bi}_{2} \mathrm{O}_{3}$ increases, while that of the $\beta$ phase decreases, by increasing the irradiation time. The corresponding transformation kinetics can also be described by the JMAK equation. UV laser irradiation appears as a suitable method to produce room temperature stable $\delta-\mathrm{Bi}_{2} \mathrm{O}_{3}$ patterns on $\mathrm{Bi}$ films, which may be of interest for electronic and optoelectronics if considering the wide range of applications for bismuth oxide materials.

\section{Acknowledgements}

The authors are indebted to Centro Conjunto de Investigación en Química Sustentable UAEM-UNAM for XPS measurements. This work was supported by MINECO through projects MAT2012-31959,
MAT2015-65274-R, CSD2009-0013 and it was partially supported by AFOSR grant FA9550-15-1-0142.

\section{Appendix A. Supplementary data}

Supplementary data related to this article can be found at http:// dx.doi.org/10.1016/j.jallcom.2017.06.263.

\section{References}

[1] G.C. Vásquez, M.A. Peche-Herrero, D. Maestre, A. Gianoncelli, J. Ramírez-Castellanos, A. Cremades, J.M. González-Calbet, J. Piqueras, Laser-induced anatase-to-rutile transition in $\mathrm{TiO}_{2}$ nanoparticles: promotion and inhibition effects by Fe and Al doping and achievement of micropatterning, J. Phys. Chem. C 119 (2015) 11965-11974.

[2] M.A. Camacho-López, L. Escobar-Alarcón, M. Picquart, R. Arroyo, G. Córdoba, E. Haro-Poniatowski, Micro-Raman study of the $\mathrm{m}-\mathrm{MoO}_{2}$ to $\alpha-\mathrm{MoO}_{3}$ transformation induced by cw-laser irradiation, Opt. Mater. 33 (2011) 480-484.

[3] Duc N. Nguyen, Linh N. Nguyen, Phuc D. Nguyen, Tran Viet Thu, Anh D. Nguyen, Phong D. Tran, Crystallization of amorphous molybdenum sulfide induced by electron or laser beam and its effect on $\mathrm{H}_{2}$-Evolving activities, J. Phys. Chem. C 120 (2016) 28789-28794.

[4] Alexey Grigoriev, Igor Polozov, Vadim Sufiiarov, Anatoly Popovich, In-situ synthesis of $\mathrm{Ti}_{2} \mathrm{AlNb}$-based intermetallic alloy by selective laser melting, J. Alloys Compd. 704 (2017) 434-442.

[5] Yuan-qing Huang, Rong Huang, Qing-lu Liu, Chang-cheng Zheng, Jiqiang Ning, Yong Peng, Zi-yang Zhang, Realization of III-V semiconductor periodic nanostructures by laser direct writing technique, Nanoscale Res. Lett. 12 (2017) 12.

[6] Mario García-Lechuga, Daniel Puerto, Yasser Fuentes-Edfuf, Javier Solís, Jan Siegel, Ultrafast moving-spot microscopy: birth and growth of laserinduced periodic surface structures, ACS Photonics 3 (2016) 1961-1967.

[7] S. Camacho-López, R. Evans, L. Escobar-Alarcón, Miguel A. Camacho-López, Marco A. Camacho-López, Polarization-dependent single-beam laser-induced grating-like effects on titanium films, Appl. Surf. Sci. 255 (2008) 3028-3032.

[8] Feng Xia, Xinzheng Zhang, Meng Wang, Qian Liu, Jingjun Xu, Analysis of the laser oxidation kinetics process of $\mathrm{In}-\mathrm{In}_{2} \mathrm{O}_{3} \mathrm{MTMO}$ photomasks by laser direct writing, Opt. Express 23 (2015) 29193-29201.

[9] L. Kumari, J. Lin, Y. Ma, Laser oxidation and wide-band photoluminescence of thermal evaporated bismuth thin films, J. Phys. D. Appl. Phys. 41 (2008) 025405.

[10] J.A. Steele, R.A. Lewis, In situ micro-Raman studies of laser-induced bismuth oxidation reveals metastability of $\mathrm{B}_{-} \mathrm{Bi}_{2} \mathrm{O}_{3}$ microislands, Opt. Mater. Express 4 (2014) 2133-2142.

[11] M. Cano-Lara, S. Camacho-López, A. Esparza García, M.A. Camacho-López, Laser-induced molybdenum oxide formation by low energy (nJ)-high repetition rate (MHz) femtosecond pulses, Opt. Mater 33 (2011) 1648-1653.

[12] Taotao Wu, Lijun Wang, Chenghua Wei, Menglian Zhou, Minbo He, Lixiong Wu, Morphology and phase structures of CW laser-induced oxide layers on iron surface with evolving reflectivity and colors, Appl. Surf. Sci. 387 (2016) 1183-1187.

[13] M. Vila, C. Díaz-Guerra, J. Piqueras, Laser irradiation-induced $\alpha$ to $\delta$ phase transformation in $\mathrm{Bi}_{2} \mathrm{O}_{3}$ ceramics and nanowires, Appl. Phys. Lett. 101 (2012) 071905.

[14] T. Cebriano, B. Méndez, J. Piqueras, Raman study of phase transitions induced by thermal annealing and laser irradiation in antimony oxide micro- and nanostructures, CrystEngComm 18 (2016) 2541-2545.

[15] R. Deska, K. Sadecka, J. Olesiak-Bańska, K. Matczyszyn, D.A. Pawlak, M. Samoć, Nonlinear plasmonics in eutectic composites: second harmonic generation and two-photon luminescence in a volumetric $\mathrm{Bi}_{2} \mathrm{O}_{3}-\mathrm{Ag}$ metamaterial, Appl. Phys. Lett. 110 (2017) 031102.

[16] Yuling Li, Matthias A. Trujillo, Engang Fu, Brian Patterson, Ling Fei, Yun Xu, Shuguang Deng, Sergei Smirnovc, Hongmei Luo, Bismuth oxide: a new lithium-ion battery anode, J. Mater. Chem. A 1 (2013) 12123-12127.

[17] Wenhua Zuo, Weihua Zhu, Dengfeng Zhao, Yunfei Sun, Yuanyuan Li, Jinping Liu, Xiong Wen (David) Lou, Bismuth oxide: a versatile high-capacity electrode material for rechargeable aqueous metal-ion batteries, Energy Environ. Sci. 9 (2016) 2881-2891.

[18] Guo Liu, Shuai Li, Yuanyuan Lu, Jing Zhang, Zhaochi Feng, Can Li, Controllable synthesis of $\alpha-\mathrm{Bi}_{2} \mathrm{O}_{3}$ and $\gamma-\mathrm{Bi}_{2} \mathrm{O}_{3}$ with high photocatalytic activity by $\alpha$ $\mathrm{Bi}_{2} \mathrm{O}_{3} \rightarrow \gamma-\mathrm{Bi}_{2} \mathrm{O}_{3} \rightarrow \alpha-\mathrm{Bi}_{2} \mathrm{O}_{3}$ transformation in a facile precipitation method, J. Alloys Compd, 689 (2016) 787-799.

[19] Xinglong Gou, Rong Li, Guoxiu Wang, Zhixin Chen, David Wexler, Roomtemperature solution synthesis of $\mathrm{Bi}_{2} \mathrm{O}_{3}$ nanowires for gas sensing application, Nanotechnology 20 (2009) 495501.

[20] Karen Barrera-Mota, Monserrat Bizarro, Micaela Castellino, Alberto Tagliaferro, Aracely Hernández, Sandra E. Rodil, Spray deposited $\beta$ $\mathrm{Bi}_{2} \mathrm{O}_{3}$ nanostructured films with visible photocatalytic activity for solar water treatment, Photochem. Photobiol. Sci. 14 (2015) 1110-1119.

[21] Simone Sanna, Vincenzo Esposito, Jens Wenzel Andreasen, Johan Hjelm, Wei Zhang, Takeshi Kasama, Søren Bredmose Simonsen, Mogens Christensen, Søren Linderoth, Nini Pryds, Enhancement of the chemical stability in 
confined $\delta-\mathrm{Bi}_{2} \mathrm{O}_{3}$, Nat. Mater. 14 (2015) 500-504.

[22] Jochen A.H. Dreyer, Suman Pokhrel, Johannes Birkenstock, Miguel G. Hevia, Marco Schowalter, Andreas Rosenauer, Atsushi Urakawa, Wey Yang Teoha, Lutz Mädle, Decrease of the required dopant concentration for $\delta-\mathrm{Bi}_{2} \mathrm{O}_{3}$ crystal stabilization through thermal quenching during single-step flame spray pyrolysis, CrystEngComm 18 (2016) 2046-2056.

[23] A. Venegas-Castro, A. Reyes-Contreras, M. Camacho-López, O. Olea-Mejía, S. Camacho-López, A. Esparza-García, Study of the integrated fluence threshold condition for the formation of $\mathrm{B}_{-} \mathrm{Bi}_{2} \mathrm{O}_{3}$ on $\mathrm{Bi}$ thin films by using ns laser pulses, Opt. Laser Technol. 81 (2016) 50-54.

[24] J.S. Lannin, J.M. Calleja, M. Cardona, Second-order Raman scattering in the group-Vb semimetals: Bi, Sb, and as, Phys. Rev. B 12 (1975) 585-593.

[25] A.L.J. Pereira, J.A. Sans, R. Vilaplana, O. Gomis, F.J. Manjón, P. RodríguezHernández, A. Muñoz, C. Popescu, A. Beltrán, Isostructural second-order phase transition of $\beta-\mathrm{Bi}_{2} \mathrm{O}_{3}$ at high pressures: an experimental and theoretical study, J. Phys. Chem. C 118 (2014) 23189-23201.

[26] M. Avrami, Kinetics of phase change I. General theory, J. Chem. Phys. 7 (1939) $1103-1112$.

[27] M. Avrami, Kinetics of phase change II. Transformation-time relations for random distribution of nuclei, J. Chem. Phys. 8 (1940) 212-224.

[28] J.W. Christian, The Theory of Transformations in Metals and Alloys: an Advanced Textbook in Physical Metallurgy, second ed., Pergamon Press, Oxford; New York, 1975.

[29] G. Mannino, C. Spinella, R. Ruggeri, A. La Magna, G. Fisicaro, E. Fazio, F. Neri, V. Privitera, Crystallization of implanted amorphous silicon during millisecond annealing by infrared laser irradiation, Appl. Phys. Lett. 97 (2010) 022107.

[30] P. Bruna, D. Crespo, R. González-Cinca, E. Pineda, On the validity of Avrami formalism in primary crystallization, J. Appl. Phys. 100 (2006) 054907.

[31] T. Pradell, D. Crespo, N. Clavaguera, M.T. Clavaguera-Mota, Kinetic theory of microstructural evolution in nucleation and growth processes, J. Phys. Condens. Matter 10 (1998) 3833-3844.

[32] J.C. Yang, D. Evan, L. Tropia, From nucleation to coalescence of $\mathrm{Cu}_{2} \mathrm{O}$ islands during in situ oxidation of $\mathrm{Cu}(001)$. Appl. Phys. Lett. 81 (2002) 241-243.

[33] Adriana M. Mihut, Arnaud Chiche, Markus Drechsler, Holger Schmalz, Emanuela Di Cola, Georg Krausch, Matthias Ballauff, Crystallization-induced switching of the morphology of poly(ethylene oxide)-block-polybutadiene micelles, Soft Matter 5 (2009) 208-213.
[34] J.A. Steele, R.A. Lewis, Laser-induced oxidation kinetics of bismuth surface microdroplets on GaAsBi studied in situ by Raman microprobe analysis, Opt. Mater. Express 22 (2014) 32261-32275.

[35] V.N. Denisov, A.N. Ivlev, A.S. Lipin, B.N. Mavrin, V.G. Orlov, Raman spectra and lattice dynamics of single-crystal $\alpha-\mathrm{Bi}_{2} \mathrm{O}_{3}$, J. Phys. Condens. Matter 9 (1997) 4967-4978.

[36] Savio J.A. Moniz, Christopher S. Blackman, Claire J. Carmal, Geoffrey Hyett MOCVD of crystalline $\mathrm{Bi}_{2} \mathrm{O}_{3}$ thin films using a single-source bismuth alkoxide precursor and their use in photodegradation of water, J. Mater. Chem. 20 (2010) 7881-7886.

[37] N.V. Skorodumova, A.K. Jonsson, M. Herranen, M. Stromme, G.A. Niklasson, B. Johansson, S.I. Simak, Random conductivity of $\delta-\mathrm{Bi}_{2} \mathrm{O}_{3}$ films, Appl. Phys. Lett. 86 (2005) 241910.

[38] H.T. Fang, X.M. Teng, S.S. Pan, C. Ye, G.H. Li, L.D. Zhang, Optical properties of $\delta$ $\mathrm{Bi}_{2} \mathrm{O}_{3}$ thin films grown by reactive sputtering, Appl. Phys. Lett. 87 (2005) 231916.

[39] L.E. Depero, L. Sangaletti, Structural disorder and ionic conduction: the case of $\mathrm{Bi}_{2} \mathrm{O}_{3}$, J. Solid State Chem. 122 (1996) 439-443.

[40] L. Shikhmanter, M. Talianker, M.P. Dariel, A tem study of the crystallization behavior in amorphous vacuum condensed $\mathrm{Er}-\mathrm{Cu}$ thin films, J. Phys. Chem. Solids 44 (1983) 745-753.

[41] Neil Birks, Gerald H. Meier, Frederick S. Pettit, Introduction to the High temperature Oxidation of Metals, second ed., Cambridge University Press, 2012.

[42] Jay A. Switzer, Mark G. Shumsky, Eric W. Bohannan, Electrodeposited ceramic single crystals, Science 284 (1999) 293-296.

[43] D.L. Proffit, G.-R. Bai, D.D. Fong, T.T. Fister, S.O. Hruszkewycz, M.J. Highland, P.M. Baldo, P.H. Fuoss, T.O. Mason, J.A. Eastman, Phase stabilization of $\delta-\mathrm{Bi}_{2} \mathrm{O}_{3}$ nanostructures by epitaxial growth onto single crystal $\mathrm{SrTiO}_{3}$ or $\mathrm{DyScO}_{3}$ substrates, Appl. Phys. Lett. 96 (2010) 021905.

[44] J. George, B. Pradeep, S. Joseph, Optical properties of $\mathrm{\beta}_{-} \mathrm{Bi}_{2} \mathrm{O}_{3}$ thin films, Phys. Stat. Sol. (a) 103 (1987) 607-612.

[45] H.A. Harwig, A.G. Gerards, The polymorphism of bismuth sesquioxide, Thermochim. Acta 28 (1978) 121-131.

[46] Deng Hong-Yan, Hao Wei-Chang, Xu Huai-Zhe, A transition phase in the transformation from $\alpha-\beta$ - and $\varepsilon$ - to $\delta$-bismuth oxide, Chin. Phys. Lett. 28 (2011) 056101 